\title{
Halogens in chondritic meteorites and terrestrial accretion
}

DOI:

10.1038/nature24625

\section{Document Version}

Accepted author manuscript

Link to publication record in Manchester Research Explorer

\section{Citation for published version (APA):}

Clay, P., Burgess, R., Busemann, H., Ruzie-Hamilton, L., Joachim, B., Day, J. M. D., \& Ballentine, C. J. (2017). Halogens in chondritic meteorites and terrestrial accretion. Nature, 551, 614-618.

https://doi.org/10.1038/nature24625

\section{Published in:}

Nature

\section{Citing this paper}

Please note that where the full-text provided on Manchester Research Explorer is the Author Accepted Manuscript or Proof version this may differ from the final Published version. If citing, it is advised that you check and use the publisher's definitive version.

\section{General rights}

Copyright and moral rights for the publications made accessible in the Research Explorer are retained by the authors and/or other copyright owners and it is a condition of accessing publications that users recognise and abide by the legal requirements associated with these rights.

\section{Takedown policy}

If you believe that this document breaches copyright please refer to the University of Manchester's Takedown Procedures [http://man.ac.uk/04Y6Bo] or contact uml.scholarlycommunications@manchester.ac.uk providing relevant details, so we can investigate your claim.

\section{OPEN ACCESS}


1 TITLE: Halogens in chondritic meteorites and terrestrial accretion

2

AUTHORS: Patricia L. Clay ${ }^{1 *}$, Ray Burgess ${ }^{1}$, Henner Busemann ${ }^{2}$, Lorraine RuziéHamilton ${ }^{1}$, Bastian Joachim ${ }^{3}$, James M.D. Day ${ }^{4}$, Christopher J. Ballentine ${ }^{5}$

*corresponding author: (patricia.clay@manchester.ac.uk)

AFFILIATIONS: ${ }^{1}$ School of Earth and Environmental Sciences, University of Manchester, Manchester, M13 9PL United Kingdom; ${ }^{2}$ Institute for Geochemistry and Petrology, ETH Zürich, Clausiusstrasse 25, 8092 Zürich, Switzerland; ${ }^{3}$ Institute for Mineralogy and Petrography, University of Innsbruck, Innrain 52, A-6020 Innsbruck, Austria; ${ }^{4}$ Scripps Institution of Oceanography, University of California San Diego, La Jolla, California 92093-0244 USA; ${ }^{5}$ Department of Earth Sciences, University of Oxford, South Parks Road, Oxford, OX1 3AN United Kingdom

INTRODUCTORY PARAGRAPH: Volatile element delivery and retention played a fundamental role in Earth's formation and subsequent chemical differentiation. The heavy halogens $(\mathrm{Cl}, \mathrm{Br}$ and $\mathrm{I})$ are key tracers of accretionary processes due to their high volatility and incompatibility, but have low abundances in most geological and planetary materials. Noble gas proxy isotopes produced during neutron irradiation provide a high sensitivity tool for the determination of heavy halogen abundance. Here we show that $\mathrm{Cl}, \mathrm{Br}$ and I abundances in carbonaceous, enstatite, Rumuruti and primitive ordinary chondrites have concentrations $\sim 6, \sim 9$ and between 15-37 times lower, respectively, than previously reported and most commonly accepted estimates ${ }^{1}$. This is independent of the chondrites' oxidation state or petrological type. Bromine $/ \mathrm{Cl}$ and $\mathrm{I} / \mathrm{Cl}$ in all studied chondrites show a limited range, indistinguishable from bulk silicate Earth (BSE) estimates. Our results demonstrate that BSE depletion of halogens relative to primitive meteorites is now consistent with lithophile elements of similar volatility. The new results for carbonaceous chondrites demonstrate that late accretion, constrained to a maximum of $0.5 \pm 0.2 \%$ of Earth's silicate mass ${ }^{2-5}$, cannot solely account for present-day terrestrial halogen inventories ${ }^{6,7}$. It is estimated that $80-90 \%$ of heavy halogens are concentrated in Earth's surface reservoirs $^{7,8}$ and have not undergone the extreme early loss observed in 
atmosphere-forming elements ${ }^{9}$. Therefore, in addition to late accretion of halogens and mantle degassing, which is $<50 \%$ efficient over Earth history ${ }^{10}$, efficient extraction of halogen-rich fluids ${ }^{6}$ from the solid Earth during the earliest stages of Earth formation is also required. The hydrophilic nature of the halogens supports this requirement, and is consistent with a volatile/water rich late-stage terrestrial accretion $^{5,11-14}$.

MAIN TEXT: Chondrites provide the reference frame for understanding the processes that controlled the accretion of the Solar System's inner planets. The depletion of highly volatile elements in the Earth relative to the carbonaceous Ivuna (CI)-type chondrites is well documented ${ }^{15}$ but, for some elements, the difference predicted from volatility, or decreasing condensation temperature $\left(50 \% \mathrm{~T}_{\mathrm{C}}\right)$, is insufficient to explain the extent of depletion actually observed. This has been particularly problematic for the heavy halogens $\mathrm{Cl}, \mathrm{Br}$ and $\mathrm{I}$, which have previously been shown to be depleted on Earth compared to $\mathrm{Cl}$ chondrite by factors of $\sim 28,46$ and 33 for $\mathrm{Cl}, \mathrm{Br}$ and $\mathrm{I}$, respectively ${ }^{16}$. For example, the degree of chlorine depletion is far higher than that of lithophile elements with similar $50 \% \mathrm{~T}_{\mathrm{C}}$, leading to models accounting for special halogen behavior during the accretionary process including; early hydrodynamic escape of hydrogen ${ }^{17}$, sequestration of halogens into an unidentified reservoir such as the core ${ }^{18,19}$, impact-driven erosive loss of halogenrich surface reservoirs on early Earth ${ }^{20}$, or a higher nebular volatility (lower $50 \% \mathrm{~T}_{\mathrm{C}}$ ) of the halogen elements ${ }^{16,21}$.

Accurate and precise knowledge of the halogen abundances in different chondrite classes is clearly essential for understanding terrestrial volatile evolution. However, progress towards characterizing the halogen abundances of chondrites has been hampered by the lack of precise measurement techniques for the particularly low abundance of $\mathrm{Br}$ and $\mathrm{I}$, coupled with the limited amounts of suitable meteorite specimens available for analysis. Approximately an order of magnitude variation in halogen abundances within individual meteorite classes was reported during the 1960s and 1970s, typically analysed using neutron activation analysis and pyrohydrolysis. Using high sensitivity neutron-irradiation noble gas mass spectrometry (NI-NGMS) (online Methods), we have determined the halogen abundances and $\mathrm{Br} / \mathrm{Cl}$ and $\mathrm{l} / \mathrm{Cl}$ ratios for 24 chondrites (Table 1, Figures 1 and 2 
and online Methods) covering four different classes; carbonaceous, enstatite, Rumuruti and ordinary chondrites.

Relative to data for other Solar System materials, including lunar, martian and terrestrial compositions, the $\mathrm{Br} / \mathrm{Cl}$ and $\mathrm{l} / \mathrm{Cl}$ variances of the carbonaceous, enstatite, Rumuruti and primitive ordinary chondrite classes are remarkably low (Fig. 1). Evidence of systematic elemental halogen fractionation during formation of chondrites is negligible. Additionally, secondary aqueous alteration is isochemical for the heavy halogens, as demonstrated by consistency in Type 1 and Type 2 chondrites (Fig. 1; online Methods). Bromine/Cl and $\mathrm{l} / \mathrm{Cl}$ in chondrites are also indistinguishable from BSE values (Fig. 1, 2). This relationship implies that mechanisms of delivery to, and retention within Earth occurred without significant fractionation of the halogens. Critically, such an observation is also independent of which chondrites are dominant sources of terrestrial material. Only the thermally metamorphosed ordinary and enstatite chondrites show distinctly different halogen concentrations and ratios. The latter is particularly evident in thermally metamorphosed ordinary and enstatite chondrite $\mathrm{I} / \mathrm{Cl}$ ratios (Fig. $1 \mathrm{~h}$ ), and explained by both their different halogen-mineralogy (e.g., phosphates, sulfides), and more extensive thermal metamorphism than experienced by the most unequilibrated chondrites (online Methods).

Halogen concentrations in this study (49 analyses of 24 chondrites) are significantly lower and show far less variation than those previously reported (Table S1 and Extended Data Figure 1). This is true for all chondrite types (Fig. 2). The discrepancy between this study and previous data can likely be attributed to differences in sample preparation techniques (e.g., possible inclusion of surface or terrestrial alteration material ${ }^{22}$; Table S2). Only the earlier studies using larger samples $(\geq 1 \mathrm{~g})^{23}$ and the more recent studies on $\mathrm{Cl}$ chondrites using gas source mass spectrometry ${ }^{24}$, are most consistent with the data presented here (Table S1). It is possible to compare halogen concentration variations in $\mathrm{Cl}$-chondrites with elements of similar volatility and geochemical affinity (moderately volatile lithophile elements). For example, the Orgueil $\mathrm{Cl}$ chondrite has potassium $\left(50 \% \mathrm{~T}_{\mathrm{C}} 1006 \mathrm{~K}^{16}\right)$ concentrations with approximately a factor of two difference $\left(365-677 \mathrm{ppm}^{25}\right)$, while $\mathrm{Rb}\left(50 \% \mathrm{~T}_{\mathrm{C}} 800 \mathrm{~K}^{16}\right)$ shows $\sim 1.5$ times variation $\left(1.68-2.47 \mathrm{ppm}^{25}\right)$. In contrast, the 
variance for $\mathrm{Cl}$-chondrite chlorine abundance has been typically reported as $\sim 700$ ppm, with $\mathrm{Cl}$ abundances ranging from $210-950 \mathrm{ppm}$ ( $\sim 4.5$ times variation). It has been suggested that the greater disparity reflects the effects of terrestrial contamination $^{26}$, sample variability ${ }^{25}$ or analytical artifacts $^{27}$ (online Methods). With these caveats in mind, particular care was taken to identify and minimize contamination or bias (online Methods; Extended Data Figures 2-4). We obtained significantly lower halogen concentrations with reduced variance of $115 \pm 36$ (weighted average error) ppm Cl, $189 \pm 71 \mathrm{ppb} \mathrm{Br}$, and $57 \pm 7$ ppb I for Cl-chondrite Orgueil (Table 1 and Table S3).

All chondrite groups, including the $\mathrm{Cl}$ chondrites, have consistently lower abundances of $\mathrm{Cl}, \mathrm{Br}$ and I than previously reported: 32 analyses of 17 unequilibrated carbonaceous, enstatite and Rumuruti chondrites give averages of (weighted average error): $111 \pm 38$ ppm Cl, $362 \pm 39$ ppb Br, and $38 \pm 3$ ppb I. One key observation from our new data is the reduced spread in $\mathrm{Cl} / \mathrm{Br} / \mathrm{l}$ ratios. All historical measurements with high $\mathrm{Cl}$ that contain a full $\mathrm{Cl} / \mathrm{Br} / \mathrm{l}$ analysis, show high $\mathrm{I} / \mathrm{Cl}$ ratios relative to the new data (Fig. 1). High I is a strong indicator of terrestrial contamination suggesting that chondritic reference concentrations have been significantly overestimated. Also, the $\mathrm{Br} / \mathrm{Cl}$ and $\mathrm{I} / \mathrm{Cl}$ signature of the $\mathrm{BSE}$ are chondritic (Fig. 1) and BSE and chondrites have identical $\delta^{37} \mathrm{Cl}$ values of $-0.1 \pm 0.4$ and $0.0 \pm 0.7 \%{ }^{24,26}$. The similarity of both halogen isotopic and elemental abundance ratios between BSE and chondrites provide key observational constraints in developing any model controlling volatile element delivery to Earth.

Our revised halogen abundances yield higher $\mathrm{Cl}$-chondrite normalized abundances of $\mathrm{Cl}, \mathrm{Br}$ and $\mathrm{I}$, demonstrating that BSE is not significantly depleted in halogens compared with lithophile elements of similar volatility (Fig. 3$)^{28}$. Although $\mathrm{Cl}$ is plotted with a $50 \% \mathrm{~T}_{\mathrm{C}}$ associated with sodalite stability ${ }^{16}$ (Fig. 3), a lower $50 \% \mathrm{~T}_{\mathrm{C}}$ for $\mathrm{Cl}$ has been suggested ${ }^{21}$ (Fig. 3). A lower condensation temperature for $\mathrm{Cl}$, similar to that of $\mathrm{Br}$ and $\mathrm{I}$, would account for the lack of fractionation observed in $\mathrm{Cl} / \mathrm{Br} / \mathrm{l}$ across the different meteorite classes examined here and BSE.

Assuming complete retention of halogens during accretion, from an average chondrite composition $(111 \pm 38 \mathrm{ppm} \mathrm{Cl}, 362 \pm 39 \mathrm{ppb} \mathrm{Br}$ and $38 \pm 3 \mathrm{ppb} \mathrm{I}$, as 
above), would lead to an overabundance by a factor of 6.5 to 7 for chlorine and bromine, and a factor of 3.5 to 3.8 for iodine in the BSE, thus requiring an efficient volatile-loss mechanism during or after accretion to achieve terrestrial abundances. A similar magnitude of loss for elements with the same range of volatility as the halogens ${ }^{29,30}$ would also be required to preserve approximately chondritic ratios in BSE. Conversely, if we consider total halogen loss during early accretion, Earth would then require $\sim 15 \%(\mathrm{Cl}$ and $\mathrm{Br})$ to $\sim 26 \%$ (I) of the terrestrial mantle's mass addition of chondrites to subsequently replenish the current terrestrial halogen inventory after accretion. This estimate is far greater than late accretion addition of $0.5 \pm 0.2 \%$ of Earth's silicate mass required to account for highly siderophile element and moderately volatile chalcophile (S-Se-Te) element compositions of the $\mathrm{BSE}^{2-4}$. Therefore, the terrestrial halogen budget cannot be accounted for by late accretion alone. More likely, a large proportion of Earth's halogens were delivered and retained during the main stages of accretion and subsequent events (e.g., Moon-forming giant impact), as found for the moderately volatile elements such as $\mathrm{Ag}^{5}$. This, however, does not preclude the addition of halogens delivered during late accretion $^{2,31}$. For example, volatile loss of $\sim 80 \%$ during accretion has been suggested for Earth ${ }^{32}$, which would correspond to $94 \% \mathrm{Cl}, 91 \% \mathrm{Br}$ and $48 \% \mathrm{I}$ of the total terrestrial halogen budget. Late accretion addition of $\sim 0.5 \pm 0.2 \%$ carbonaceous chondrite material ${ }^{31}$ would supplement the halogen budget to $\sim 100 \%$ $\mathrm{Cl}, 97 \% \mathrm{Br}$ and $51 \% \mathrm{l}$, of current terrestrial budgets. We do not place significance on the difference between I and $\mathrm{Cl}-\mathrm{Br}$, which is accommodated within the uncertainty of the BSE iodine estimate (online Methods; Table S4 and S5).

The limited variation in the $\mathrm{Br} / \mathrm{Cl}$ and $\mathrm{I} / \mathrm{Cl}$ ratio of chondrites provides a firm reference; irrespective of the detail of the mix of primitive materials with chondritelike composition or sequence that accreted to form the Earth. This implies that primitive materials forming early in Solar System history should have a limited range in halogen compositions, regardless of their accretionary source. Additionally, the similarity of the $\mathrm{Cl} / \mathrm{Br} / \mathrm{l}$ ratio of $\mathrm{BSE}$ to our new average chondrite reference means that the accretionary process delivering and preserving BSE halogens did not significantly fractionate their elemental composition. Mass-dependent processes loss to account for putative excessive halogen BSE depletion relative to elements of 
171 similar volatility, are unnecessary in light of the new chondrite results. Our results 172 demonstrate that the likely terrestrial building blocks had significantly lower and unfractionated halogen concentrations than previously recognised.

175 Unlike other lithophile elements of similar volatility, an estimated $\sim 80-90 \%$ of the 176 heavy halogens on Earth are sequestered in the surface reservoirs (crust, 177 sediments, oceans) $)^{7,8}$. The mantle degassing efficiency, measured by K-derived ${ }^{40} \mathrm{Ar}$ 178 in the atmosphere, at ca. $50 \%{ }^{10}$, cannot account for this halogen distribution, which must represent an early accretionary process. Notwithstanding late delivery of halogens to the exosphere, the implication is that the Earth's mantle was efficiently depleted in halogens to surface reservoirs relatively early in Earth's history. The

182 terrestrial record of ${ }^{129} \mathrm{I}$ and ${ }^{244} \mathrm{Pu}$-derived xenon isotopes is unequivocal in showing 183 almost complete lack of retention of atmophile volatiles in the first ca. $100 \mathrm{Ma}$ of 184 Earth history ${ }^{9,33}$. To prevent the halogens from being lost from the Earth system after their transfer to the terrestrial surface reservoirs, the heavy halogens must have been retained at the surface in a non-gaseous state. The hydrophilic nature of the halogens both in hydrous melts ${ }^{6}$ and aqueous solution may provide the unique combination of processes required to account for the modern terrestrial halogen distribution; of wet melting through efficient extraction from the solid Earth and retention within water-rich near-surface phases during the earliest stages of Earth 191 formation ${ }^{14}$. 


\section{REFERENCES (MAIN TEXT):}

1. Dreibus, G., Spettel, B. \& Wänke, H. Halogens in meteorites and their primordial abundances. Phys. Chem. Earth 11, 33-38 (1979).

2. Chou, C.-L. Fractionation of siderophile elements in the earth's upper mantle. Proc. $9^{\text {th }}$ Lunar Planet. Sci. Conf. 219-230 (1978).

3. Day, J. M. D., Brandon, A. D. \& Walker, R. J. Highly siderophile elements in Earth, Mars, the Moon \& Asteroids. In: Reviews in Mineralogy and Geochemistry 81, 161-238 (2016).

4. Wang, Z. \& Becker, R. Ratios of $S, S e$ and Te in the silicate Earth require a volatile-rich late veneer. Nature 499, 328-331 (2013).

5. Schönbächler, M., Carlson, R., Horan, M., Mock, T. \& Hauri, E. H. Heterogeneous accretion and the moderately volatile element budget of the earth. Science 328, 884-887 (2010).

6. Aiuppa, A., Baker, D. R. \& Webster, J. D. Halogens in volcanic systems. Chem. Geol. 263, 1-18 (2009).

7. Kendrick, M. A., Hèmond, C, Kamenetsky, V.S., Danyushevsky, L., Devey, C.W., Rodermann, T., Jackson, M.G., \& Perfit, M.R. Seawater cycled throughout Earth's mantle in partially serpentinized lithosphere. Nat. Geosci. 10, 223-229 (2017).

8. Burgess, R., Layzelle, E., Turner, G. \& Harris, J. W. Constraints on the age and halogen composition of mantle fluids in Siberian coated diamonds. Earth Planet. Sci. Lett. 197, 193-203 (2002).

9. Pepin, R. O. \& Porcelli, D. Xenon isotope systematics, giant impacts, and mantle degassing on the early Earth. Earth Planet. Sci. Lett. 250, 470-485 (2006).

10. Allègre, C. J., Hofmann, A. W. \& O'Nions, K. The argon constraints on mantle structure. Geophys. Res. Lett. 23, 3555-3557 (1996).

11. Tucker, J. M. \& Mukhopadhyay, S. Evidence for multiple magma ocean outgassing and atmospheric loss episodes from mantle noble gases. Earth Planet. Sci. Lett. 393, 254-265 (2014).

12. Mukhopadhyay, S. Early differentiation and volatile accretion recorded in deep-mantle neon and xenon. Nature 486, 101-104 (2012). 
13. Halliday, A. N. The origin of volatiles in the terrestrial planets. Geochim. Cosmochim. Acta 105, 146-171 (2013).

14. Elkins-Tanton, L. T. Formation of early water oceans on rocky planets. Astrophys. Space Sci. 332, 359-364 (2011).

15. Allègre, C. J., Poirier, J. P., Humler, E. \& Hofmann, A. W. The chemical composition of the Earth. Earth Planet. Sci. Lett. 134, 515-526 (1995).

16. Lodders, K. Solar system abundances and condensation temperatures of the elements. Astrophys. J. 591, 1220-1247 (2003).

17. Kramers, J. D. Volatile element abundance patterns and an early liquid water ocean on Earth. Precambrian Res. 126, 379-394 (2003).

18. Armytage, R. M. G., Jephcoat, A. P., Bouhifd, M. A. \& Porcelli, D. Metalsilicate partitioning of iodine at high pressures and temperatures: Implications for the Earth's core and ${ }^{129^{*}}$ Xe budgets. Earth Planet. Sci. Lett. 373, 140-149 (2013).

19. McDonough, W. F. Compositional model for the Earth's core. In: Treatise On Geochemistry, 547-568 (Elsevier, 2003). doi:10.1016/B0-08-043751-6/020156.

20. Sharp, Z. D. \& Draper, D. S. The chlorine abundance of Earth: Implications for a habitable planet. Earth Planet. Sci. Lett. 369-370, 71-77 (2013).

21. Zolotov, M. Y. \& Mironenko, M. Hydrogen chloride as a source of acid fluids in parent bodies of chondrites. Lunar Planet. Sci. Conf. XXXVIII, Abstr. 2340 (2007).

22. Krähenbühl, U., Morgan, J. W., Ganapathy, R. \& Anders, E. Abundance of 17 trace elements in carbonaceous chondrites. Geochim. Cosmochim. Acta 37, 1353-1370 (1973).

23. Allen, R. O. J. \& Reed, G. W. J. Cl, Br and I in chondrites. Eos Trans. Am. Geophys. Union 46, 123-124 (1965).

24. Sharp, Z. D., Barnes, J.D., Brearley, A.J., Chaussidon, M., Fischer, T.P. \& Kamenetsky, V.S. Chlorine isotope homogeneity of the mantle, crust and carbonaceous chondrites. Nature 446, 1062-1065 (2007).

25. Barrat, J. A., Zanda, B., Moynier, F., Bollinger, C., Liorzou, C. \& Bayon, G. Geochemistry of $\mathrm{Cl}$ chondrites: Major and trace elements, and $\mathrm{Cu}$ and $\mathrm{Zn}$ Isotopes. Geochim. Cosmochim. Acta 83, 79-92 (2012). 
26. Sharp, Z. D., Mercer, J.A., Jones, R.H., Brearley, A.J., Selverstone, J., Bekker, A, \& Stachel, T. The chlorine isotope composition of chondrites and Earth. Geochim. Cosmochim. Acta 107, 189-204 (2013).

27. Reed, G. W. J. \& Allen, R. O. J. Halogens in chondrites. Geochim. Cosmochim. Acta 30, 779-800 (1966).

28. McDonough, W. F., Sun, S., Ringwood, A., Jagoutz, E. \& Hofmann, A. W. Potassium, rubidium, and cesium in the Earth and Moon and the evolution of the mantle of the Earth. Geochim. Cosmochim. Acta 56, 1001-1012 (1992).

29. Palme, H. \& O'Neill, H. S. C. in Cosmochemical estimates of mantle composition. Treatise on Geochemistry 1-38 (Elsevier, 2003). doi:10.1016/B978-0-08-095975-7.00201-1

30. McDonough, W. F. \& Sun, S.-S. The composition of the Earth. Chem. Geol. 120, 223-253 (1995).

31. Marty, B. The origins and concentrations of water, carbon, nitrogen and noble gases on Earth. Earth Planet. Sci. Lett. 313-314, 56-66 (2012).

32. Humayun, M. \& Cassen, P. Processes determining the volatile abundance of the Earth and Moon, In: The Origin of the Earth and Moon (eds. Canup, R. M. \& Righter, K.) 3-23 (Arizona University Press, 2000).

33. Tucker, J. M., Mukhopadhyay, S. \& Schilling, J.-G. The heavy noble gas composition of the depleted MORB mantle (DMM) and its implications for the preservation of heterogeneities in the mantle. Earth Planet. Sci. Lett. 355356, 244-254 (2012). 
279 ACKNOWLEDGEMENTS: We acknowledge the following organisations and 280 individuals for the provision of samples: NASA Antarctic Meteorite Working Group 281 (MIL 07139, MIL 07028 and ALH 77295); P. Heck, Chicago Field Museum (Indarch); 282 Izikio Museum of South Africa (St. Marks); M. Boyet (SAH 97096); M. Schönbächler 283 (GRA 06100, EET 92159, Murray, Orgueil); and A. Ruzicka (NWA 753 and NWA 284 755). We thank J. Cowpe for assistance with noble gas measurements, K.J. Theis 285 for laboratory assistance and W. Akram for help with sample preparation. This 286 project was funded by the European Research Council (ERC) FP7 'NOBLE' grant 287 No. 267692.

288 AUTHOR CONTRIBUTIONS: PLC, RB and CJB designed the study. PLC and HB acquired the samples, with material also provided by JMDD. PLC analysed the 290 samples and wrote the first manuscript draft. All authors contributed to the 291 discussion of the results, interpretation of the data, and editing of the manuscript.

292 AUTHOR INFORMATION: Reprints and permissions information is available at 293 www.nature.com/reprints. The authors declare no competing financial interests.

294 Readers are welcome to comment on the online version of the paper.

295 Correspondence and requests for materials should be addressed to PLC 296 (patricia.clay@manchester.ac.uk). 
FIGURE 1 Bromine/CI and I/CI for chondrites and planetary materials. Observed variation for $\mathrm{Br} / \mathrm{Cl}$ and $\mathrm{l} / \mathrm{Cl}$ in chondrites is small relative to reference materials: $\sim 5 \times$ in carbonaceous chondrites (CC) and $\sim 3-6 \times$ in enstatite chondrites (EC). (a, e) Martian meteorites (refs. 41-43); (b, f) Lunar materials, including lunar volcanic glass (LVG, refs. 44-48), (c, g) back arc basin basalts (BABB; refs. 49,50), ocean-island basalts (OIB, ref. 49), diamonds (ref. 8), mid-ocean ridge basalts (MORB, refs. 5153), serpentinites (refs. 54,55), and seawater (ref 56). $\mathrm{Br} / \mathrm{Cl}$ and $\mathrm{l} / \mathrm{Cl}$ chondrite data from this study $(\mathrm{d}, \mathrm{h})$. BSE halogen ratio is represented by the light grey band (Table S4). Open symbols are petrologic Type 5/6. RC = Rumuruti chondrites, $O C=$ ordinary chondrites. Error bars represent the square root of the sum of weight factors.

FIGURE 2. Bromine (A) and $I(B)$ (ppb) versus $C l$ abundance (ppm) in carbonaceous, enstatite, ordinary and Rumuruti chondrites. Previous $\mathrm{Cl}$ chondrite data ${ }^{26,57-59}$ are shown as grey triangles and exclude several lower concentration Cl measurements (290-320 ppm in Ivuna and Orgueil and 510 ppm in Tonk; see Table S1 that do not have corresponding $\mathrm{Br}$ or I concentrations. $\mathrm{BSE} \mathrm{Br} / \mathrm{Cl}$ and $\mathrm{I} / \mathrm{Cl}$ average from various sources (see Table S4 in the Supplement for dataset and references). Dashed line in each panel represent fit to the $\mathrm{CC}, \mathrm{EC}$ and $\mathrm{RC}$ data (indistinguishable from fit to $\mathrm{CC}$ data alone in each case). Colour = meteorite group. Shape $=$ petrologic type. Error bars represent the square root of the sum of weight factors.

FIGURE $3 \mathrm{Cl}$-Chondrite and Mg-normalized bulk silicate Earth abundances as a function of $50 \% \mathrm{~T}_{\mathrm{c}}$. Open green circles represent previously determined $\mathrm{Cl}$ chondrite $\mathrm{Cl}, \mathrm{Br}$ and I abundances, green stars are calculated using revised abundances presented here. Dashed lines between the data sets illustrate magnitude of change. Late accretion of a chondritic component of $0.5 \pm 0.2 \%$ the BSE mass defined by the highly siderophile elements, Se, Te, S and C estimated abundances is shown in grey [refs. 2,4 and references therein]. The $50 \% \mathrm{~T}_{\mathrm{C}}$ for $\mathrm{Cl}$ based on sodalite stability is shown with lower estimates ${ }^{21}$, indicated by the purple 
330 arrow. Geochemical affinity (shape), volatility classification (colour) and 50\% TC: ref 33116. 
333 Sample Selection. Twenty-four meteorite samples, falls and finds, were analysed,

334

335

336

337

338

339

340

341

342

343

344

345

346

347

348

349

350

351

352

353

354

355

356

357

358

359

360

361

362

363

364 including six carbonaceous, seven ordinary, seven enstatite, two Rumuruti chondrites, and the Kakangari chondrite. These samples were selected to represent a diverse population of primitive meteorites covering variations in clan and petrologic type, in order to investigate the effects of aqueous and thermal metamorphism on halogen abundances. The selected carbonaceous chondrites were: Orgueil ( $\mathrm{Cl}$, fall), Murray (CM2, fall), Sutter's Mill (C, fall), Murchison (CM2, fall), Graves Nunataks (GRA) 06100 (CR2, find), Elephant Moraine (EET) 92159 (CR2, find), Efremovka (reduced CV3, fall) and Allende (oxidized CV3, fall). Ordinary chondrites included only falls: Clovis (H3.6), Forrest Vale (H4), Bishunpur (LL3.15), Chelyabinsk (LL5), Barratta (L4), Barwell (L5) and Novato (L6). The selected enstatite chondrites include: Allan Hills (ALH) 77295 (EH3, find), Sahara (SAH) 97096 (EH3, find), Miller Range (MIL) 07139 (EH3, find), MIL 07028 (EH3, find), Indarch (EH4, fall), St. Mark's (EH5, fall) and Daniel's Kuil (EL6, fall). Rumuruti chondrites finds Northwest Africa (NWA) NWA 755 (R3.7) and 753 (R3.9) were also included. Detailed descriptions, including sample masses, modal mineralogy, preparation techniques and allocating institutions are provided in the below and in Tables S1-S3.

Experimental Methods. Halogen abundances were determined by neutron irradiation noble gas mass spectrometry (NI-NGMS). Details of the noble gas method for halogen analysis have been described in detail in ref. 34 . The method utilises the neutron-induced conversion of $\mathrm{Cl}, \mathrm{Br}$, and I into the respective noble gas proxy isotopes ${ }^{38} \mathrm{Ar}_{\mathrm{Cl}},{ }^{80,82} \mathrm{Kr}_{\mathrm{Br}}$ and ${ }^{128} \mathrm{Xe}_{\mathrm{I}}$. During irradiation, fast neutrons (>1 MeV) activate the reactions ${ }^{39} \mathrm{~K}(\mathrm{n}, \mathrm{p}){ }^{39} \mathrm{Ar}$ and ${ }^{40} \mathrm{Ca}(\mathrm{n}, \alpha){ }^{37} \mathrm{Ar}$. Thermal and epithermal neutrons produce noble gas isotopes from halogens through the $(n, \gamma)$ reaction. These reactions produce noble gases in amounts that are easily measured through conventional noble gas mass spectrometry. NI-NGMS has the benefit of being the most sensitive technique for measurement of heavy halogens in small, bulk samples. After irradiation, halogen abundances can be determined using monitor minerals of known halogen composition, which allows for correction of noble gas production through epithermal neutrons. Depending upon the neutron fluxes, the conversion efficiency during irradiation is typically about $1: 10^{5}$ (i.e., only 1 in every 100,000 
parent halogen isotope atoms is converted to a noble gas isotope). However, inclusion of standards with halogen concentrations determined independently by other techniques ${ }^{35-37}$, irradiated together with the samples, enables the parent halogen abundances to be accurately calculated from neutron-produced noble gas isotopes $^{34,38}$. The external errors $(2 \sigma)$ are $4 \%$ for $\mathrm{Cl}, 7 \%$ for $\mathrm{Br}$ and $5 \%$ for I, based on the BB1 scapolite monitor.

Sample Preparation and Irradiation. Terrestrial alteration can be problematic for halogen analyses, therefore extreme caution was exercised with sample handling, storage and preparation techniques, to avoid inclusion of surface, weathered, crack or vein material that may be affected by terrestrial alteration. All samples analysed in the current study are given in Table $\mathbf{S 2}$ with sample masses and preparation details. In order to avoid any potential terrestrial contamination issues associated with falls, particularly those from hot and cold desert environments where leaching and/or deposition of halogens on the surface can occur, we took particular care in our sample storage, handling and preparation. Samples were stored in desiccators within Class 1000 clean rooms prior to preparation. Any visible alteration, terrestrial weathering or fusion crust material was generously removed prior to preparation. Sample material was excavated from the interior portion of the sample only. This material was then carefully examined for any indication of terrestrial contamination (see below). Prior to irradiation, samples were either crushed into small chips and sieved, or aliquots extracted from powdered, larger main masses (e.g., 1-2 mg sized aliquots from up to $1.5 \mathrm{~g}$ sample) where possible (see below for details and a discussion about sample heterogeneity). Small samples were wrapped in Al-foil and, interspersed with monitor minerals, encapsulated under vacuum in $\mathrm{SiO}_{2}$-glass tubing before packing in $\mathrm{Al}$ canisters for irradiation. Irradiation was done in two batches at the Petten Reactor, Netherlands (MN12f and MN13), continuously over a 24-hour period. A further two samples were irradiated at the Oregon State University (OSU) reactor (MN14a) in a stepped fashion over a 2-month period for a total of $\sim 280$ hours. The neutron fluence was monitored in each irradiation with conventional ${ }^{40} \mathrm{Ar}-$ ${ }^{39} \mathrm{Ar}$ and I-Xe geochronological standards "Hb3Gr" hornblende $\left(1080.4 \pm 1.1 \mathrm{Ma}{ }^{39}\right)$ and enstatite separated from the Shallowater aubrite $\left({ }^{129} \mathrm{I} /{ }^{127} \mathrm{I}_{\text {initial }}=1.072 \times 10^{-4,40}\right)$. Scapolite minerals ("BB-1" and "SP" ${ }^{34,35}$ ) were used to monitor for epithermal neutron fluence. Thermal and epi-thermal neutron fluxes were estimated as $\sim 6.3 \mathrm{x}$ 

$\mathrm{cm}^{-2}$ for MN13 and $\sim 6.5 \times 10^{18} \mathrm{n} \mathrm{cm}^{-2}$ and $\sim 9.5 \times 10^{17} \mathrm{n} \mathrm{cm}^{-2}$ for MN14a.

Laser-heating and mass spectrometry. Argon, $\mathrm{Kr}$ and $\mathrm{Xe}$ were released from irradiated samples using a Nd:YAG infrared laser. Typical sample masses of 0.25 $3.0 \mathrm{mg}$ were either incrementally heated with increasing temperature or in single fusion analyses with a second heating step to ensure complete extraction, on the static vacuum MS1 mass spectrometer at the University of Manchester. Argon isotopes were measured using a Faraday detector $\left(10^{11}\right.$ or $10^{10} \mathrm{Ohm}$ resistor) while $\mathrm{Kr}$ and $\mathrm{Xe}$ isotopes were measured using a channeltron electron multiplier. Released gases were purified using hot and room temperature SAES ${ }^{\circledR}$ NP10 getters for a combined total of up to 20 minutes prior to analysis. All isotopes we measured in seven cycles over a 50-55 minute period using peak-jumping mode. Identical analytical procedures as for samples were employed for blank and air calibration measurements, though monitors were heated using a resistance furnace.

A further two samples (Murchison and Allende) were analysed using a ThermoFisher ARGUS VI, a low volume $\left(680 \mathrm{~cm}^{3}\right)$, Nier-type, static vacuum mass spectrometer designed for multi-collection of Ar isotopes. The ARGUS VI has five Faraday cups and a low mass compact discrete dynode (CDD) ion counting multiplier. Gases were released from meteorite samples using a 55W CETAC Fusions $\mathrm{CO}_{2}$ laser with a 3 $\mathrm{mm}$ beam diameter. Samples were fused in a single step of $0.5 \%$ to $12 \%$ power. After release, gases were purified using an NP10 hot getter and then transferred onto a liquid $\mathrm{N}_{2}$-cooled charcoal finger for five minutes. The finger was warmed to $\sim 60^{\circ} \mathrm{C}$ to release the gases. A trap current of $230 \mu \mathrm{A}$ and an acceleration voltage of $2.5 \mathrm{kV}$ were used. We report typical sensitivities of: $1.2 \times 10^{-12} \mathrm{~cm}^{3} \mathrm{fA}^{-1} \mathrm{Ar}, 7.7 \times 10^{-}$ ${ }^{13} \mathrm{~cm}^{3} \mathrm{fA}^{-1} \mathrm{Kr}$, and $9.5 \times 10^{-13} \mathrm{~cm}^{3} \mathrm{fA}^{-1} \mathrm{Xe}$. After nine measurement cycles, isotope abundances were determined by regression to inlet time.

Data Reduction. All isotopes were corrected for extraction line blanks, which typically contributed $<1 \%$ of ${ }^{38} \mathrm{Ar}$ and $<<1 \%$ for ${ }^{80} \mathrm{Kr}$ and ${ }^{128} \mathrm{Xe}$. All Ar measurements were corrected for mass discrimination, the radioactive decay of ${ }^{37} \mathrm{Ar}_{\mathrm{Ca}}$ and ${ }^{39} \mathrm{Ar}_{\mathrm{K}}$ between irradiation and analysis time, and for neutron-produced interference reactions. Corrections for air, trapped or cosmogenic contributions based on ${ }^{36} \mathrm{Ar}$ 
were executed on a sample-by-sample basis. Krypton and $\mathrm{Xe}$ isotopes were corrected for neutron-induced fission of ${ }^{235} \mathrm{U}$ using ${ }^{134} \mathrm{Xe}$. Where necessary, a small trapped correction (a mixture of air, solar wind and $Q$ gas), was applied to $X e$ isotopes based on ${ }^{130} \mathrm{Xe}$. Krypton and Xe were corrected for epithermal neutron production using the scapolite monitor minerals BB1 and BB2/SP and the Shallowater aubrite.

Halogens in chondrites: previous studies and the $\mathrm{Cl}$ reference value. Halogen determinations of chondritic materials were predominantly carried-out in the 1960's and 1970's, mainly by neutron activation analysis, and yielded variable concentrations and $\mathrm{I} / \mathrm{Cl}$ ratios an order of magnitude above known terrestrial reservoirs. These measurements were generally on relatively large samples masses (e.g., hundreds of $\mathrm{mg}$ ). Notably low or high determinations were sometimes excluded from these studies, particularly for $\mathrm{Br}$ and I, on the basis of suspected poor analyses, or suspected halogen addition from contamination or loss during weathering. Compilations, which produce commonly quoted 'reference values' for halogens in $\mathrm{Cl}$ chondrites (Table S1) are updated and extended when new data become available. However, these bulk values are based on primary data from comparatively few studies and variations within each data-set exceed analytical errors on the individual determinations. There is a relatively large data set for chlorine in $\mathrm{Cl}$ chondrites based on two samples, Orgueil and Ivuna. For example, in one compilation study ${ }^{16}$ chlorine abundance is estimated from nine analyses of Orgueil and two analyses of Ivuna $(\mathrm{Cl}$

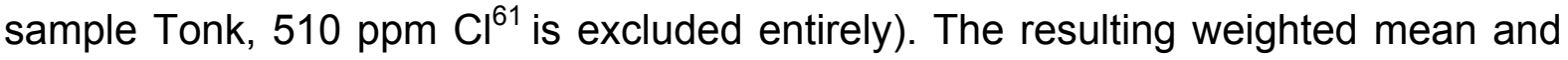
weighted mean error, calculated from the comprehensive data compilation by Lodders, $704 \pm 10$ ppm chlorine in $\mathrm{Cl}$ chondrites, suggests a good level of certainty. However, this value excludes the lowest values of 210 and 290 ppm Cl in Orgueil ${ }^{27,62}$ and 240 and 320 ppm $\mathrm{Cl}$ in Ivuna ${ }^{27}$, and the uppermost high determination of 849 ppm $\mathrm{Cl}$ in Orgueil $^{58}$. More recent studies using gas source mass spectrometry have measured chlorine in Ivuna $(290 \text { ppm) })^{24}$ and Orgueil $\left(580,603\right.$ and 630 ppm) ${ }^{26}$ (see

Extended Data Figure 1). If all published values are included, then the total spread in published chlorine concentrations in $\mathrm{Cl}$ chondrites is between 210-950 ppm, a variation of a factor of 4.5. Bromine is calculated from three samples (with the addition of $\mathrm{Cl}$ chondrite Alais) showing a factor of two difference between the highest (4.82 ppm, Ivuna) and the lowest (2.35 ppm, Alais ${ }^{63}$ ), with one analysis of Tonk 
excluded $\left(9 \mathrm{ppm} \mathrm{Br}^{61}\right)$. This discrepancy is not well reflected in the final reported value of $3.43 \pm 0.75 \mathrm{ppm}$ bromine ${ }^{11}$. The case for iodine is similar, where the mean of $0.48 \pm 0.16 \mathrm{ppm}$ is based on six analyses from Orgueil, excluding four analyses from Ivuna (1.12 $\pm 0.51 \mathrm{ppm})$. Quoted bromine and iodine abundances are sometimes calculated indirectly, due to the observed variability between the samples of Orgueil, Ivuna and Alais, relying instead on $\mathrm{Br} / \mathrm{In}, \mathrm{Br} / \mathrm{Cd}$ and $\mathrm{I} / \mathrm{In}$ and $\mathrm{I} / \mathrm{Cd}$ ratios in $\mathrm{CO}, \mathrm{CV}$, and enstatite chondrites to calculate the bromine and iodine from $\mathrm{Cl}$ values of In and $\mathrm{Cd}^{63}$.

Variations are typically attributed to: terrestrial contamination during residence at the Earth's surface ${ }^{27}$; hydrothermal transport processes on the meteorite parent body ${ }^{34}$; or analytical artefacts ${ }^{22}$. The problem is clear - there are only nine $\mathrm{Cl}$ or ' $\mathrm{Cl}$-like chondrites' and of these samples, only two (Orgueil and Ivuna) have multiple analyses, due to either low sample mass or the lack of availability of the other samples. As such, our understanding of the benchmark Solar System halogen abundances is derived from 11 analyses for chlorine, 30 analyses for bromine and six analyses for iodine, across two samples, with numerous outliers excluded from the resultant averages. Thus, the concentration variations are likely much greater than reported, particularly for trace elements such as the halogens - the literature would suggest at least a factor of four for chlorine, six for bromine and eight for iodine. There is minimal bulk data for the ordinary chondrites, with the majority being for $\mathrm{H}$ and $\mathrm{L}$ chondrites. These samples show highly variable halogen concentrations and ratios. This variation is likely heterogeneity controlled by the modal proportions of halogen-rich phases, such as $\mathrm{Cl}$-bearing phosphates and by the effects of thermal metamorphism (see main text Figure $\mathbf{1} \mathbf{d}+\mathbf{h}$ ). This is partly the reason why there was a focus on Type 4-6 ordinary chondrites in this study, in order to evaluate the effect of thermal metamorphism. This variation is also seen in the enstatite chondrites, where data from early studies were often discarded as 'anomalous' due to their high concentrations. High concentrations in the enstatite chondrites may indeed be real, due to the unique environment (nebular gas with a composition of $\mathrm{C} / \mathrm{O}>>1$; see discussion by Rubin and $\mathrm{Choi}^{64}$ ) in which they formed and should not necessarily be discarded, but instead may provide insights into halogen behavior under a special set of conditions which may be relevant to early Earth environments. 
Modal mineralogy. Halogens are present in varying amounts in silicate, phosphate and sulfide carrier phases. Important carrier phases may include sodalite, djerfisherite, lawrencite, etc. An understanding of the likely distribution of some of these carrier phases in different chondrite classes can aid in interpretation of halogen concentration data. A general modal abundance of components including matrix, chondrules, metal, calcium-aluminum rich inclusions (CAI) and amoeboid olivine aggregates (AOA), is given below in Table $\mathbf{5 6} \mathbf{6}^{\mathbf{7 2}}$ and a more specific modal mineralogy of clans from previous studies ${ }^{73-78}$ also listed. Likely halogen carriers for each clan are italicised.

Testing for surficial terrestrial contamination. Halogens show enrichment in surface environments including both hot and cold deserts. At the surface, minor contributions from anthropogenic ${ }^{79}$ and natural biological organohalogen compounds $^{80}$ are known, as well as halogens derived from marine aerosols ${ }^{81}$. The presence of these reactive halogen sources necessitates a consideration of what, if any, effect these have on halogen abundance measurements in meteorites. This is notable in polar ice regions, particularly the Antarctic (where many meteorites are collected annually), with biological production of organoiodine (e.g., methlyiodide) enhanced at sea ice margins and where there is potential for deposition of halogenbearing sea-salt; indeed instances of iodine contamination in cracks on exterior surfaces of Antarctic meteorites have been documented ${ }^{82}$. Extreme care was taken during sample preparation (see above) to ensure selection of interior material to avoid terrestrial contamination issues. Despite this, we assessed potential contamination by examining different sample populations for terrestrial weathering, aerosol deposition, and other contaminants through the following processes: (1) hot and cold desert meteorites were compared to non-Antarctic and non-desert meteorites (Extended Data Figure 2); (2) meteorite 'falls' and meteorite 'finds' were compared (Extended Data Figure 3); (3) halogen results were plotted with known terrestrial contaminants for identification of contributions (Extended Data Figure 4); (4) modal mineralogy was compared to halogen chemistry to determine the likelihood that halogens came from an indigenous source, rather than terrestrial atmospheric contamination (see Tables S6); and (5) noble gas isotope ratios (e.g., ${ }^{40} \mathrm{Ar} /{ }^{36} \mathrm{Ar}$ ) and other accessible neutron-induced elements (e.g., K, Ca, Ba) were used to support identification of terrestrial contamination. 
531 One sample (MIL 07139) consistently suffered from contamination issues in the lowtemperature steps, identified and characterised by high potassium (monitored by concomitant ${ }^{39} \mathrm{Ar}_{\mathrm{K}}$ release) concentrations (possibly deposition of $\mathrm{a} \mathrm{K}_{2} \mathrm{SO}_{4}$ salt) of up to $2.85 \mathrm{wt}$ \% compared to a more typical potassium concentration of $\sim 800 \mathrm{ppm}$ in $\mathrm{EH}$ chondrites $^{67}$. Paired sample MIL 07028 from the same Miller Range icefield seems unaffected. Additionally, EH3 SAH 97096 from the Sahara Desert is affected by either a contaminant with a high-bromine component or more likely, leaching of chlorine (Extended Data Figure 4). The lowest-temperature step data was removed and the resultant halogen totals are therefore a minimum value, though the relative consistency of results between three different sample aliquots suggests that it in indigenous component $(26 \pm 2,30 \pm 2$ and $33 \pm 2$ ppm Cl$)$.

Halogen condensation and secondary alteration in chondrites. The pronounced difference in mineralogy (Table S6) and the heterogeneous nature of matrix, chondrules and inclusions amongst the $\mathrm{C}, \mathrm{E}$ and $\mathrm{R}$ chondrites sits in stark contrast to the narrow range of observed concentrations and $\mathrm{Br} / \mathrm{Cl}$ and $\mathrm{I} / \mathrm{Cl}$ values in these meteorite groups. This provides a unique view on how the halogens condensed out of the solar nebula and their response to, and redistribution during, secondary processing (aqueous alteration and thermal metamorphism). Assuming equilibrium condensation from a gas of solar composition, primary halogen condensation host phases are predicted to be sodalite $\left(50 \% \mathrm{~T}_{\mathrm{C}}=948 \mathrm{~K}\right)$ for chlorine and $\mathrm{CaBr}_{2}$ and $\mathrm{Cal}_{2}$ in apatite (544 and $533 \mathrm{~K} 50 \% \mathrm{~T}_{\mathrm{C}}$ respectively ${ }^{16}$ ) for bromine and iodine. (We note, however, that there is significant uncertainty in the $50 \% \mathrm{~T}_{\mathrm{C}}$ determinations for the halogens and lower estimations do exist ${ }^{21}$.) There is significant uncertainty in these predicted phases with Type 1 and 2 chondrites losing their primary minerals through aqueous alteration. Secondary phases which are the result of aqueous or thermal processing such as serpentine $\left[\left(\mathrm{Mg}, \mathrm{Fe}_{3} \mathrm{Si}_{2} \mathrm{O}_{5}(\mathrm{OH})_{4}\right]\right.$, are however, capable of accommodating halogen ions substituting for $\mathrm{OH}^{-}$(up to $0.5 \mathrm{wt} \%$ chlorine) ${ }^{84}$ due to the large vacancies in the lattice structure. Hydrated, brecciated and matrix-rich, the CM chondrites also contain abundant phyllosilicates. CV chondrite halogen

560 budgets are likely dominated by the less abundant but chlorine-rich, sodalite 561 ( $\mathrm{Na}_{8} \mathrm{Al}_{6} \mathrm{Si}_{6} \mathrm{O}_{24} \mathrm{Cl}_{2} ; \sim 7$ wt. \% chlorine and up to $7 \%$ modal abundance). 
Pervasive aqueous alteration of Type 1 and Type 2 chondrites has replaced all primary silicates with hydrous secondary minerals. Lack of evidence for systematic fractionation of $\mathrm{Br} / \mathrm{Cl}$ and $\mathrm{I} / \mathrm{Cl}$ ratios (main text Fig. 1) suggests that the halogens were quantitatively redistributed during the aqueous alteration of $\mathrm{Cl}$ (type 1) and $\mathrm{CM}$ (type 2) material isochemically. This is probably due to the limited fluid flow and short length scales for water transport (10-100s $\mu \mathrm{m})$ during alteration, as suggested by Bland et al. ${ }^{80}$, in their study documenting low permeability $\left(10^{-19}\right.$ to $\left.10^{-17} \mathrm{~m}^{2}\right)$ in chondritic materials (though we note this is not universally observed, e.g., for Au redistribution ${ }^{85}$ ). Our data indicates that bulk halogen abundances have not been affected by aqueous alteration, and therefore type 1 and 2 altered chondrite samples (along with pristine type 3 chondrites) are likely to be representative of the nebula environment in which they formed.

Thermally metamorphosed ordinary chondrites, however, are distinct from these clans. Major halogen-bearing species in the OCs include silicates (feldspars, chlorine-rich glass in chondrule mesostasis) but more importantly, the halogen-rich phosphate-group mineral, apatite $\left[\mathrm{Ca}_{5}\left(\mathrm{PO}_{4}\right)_{3}(\mathrm{OH}, \mathrm{F}, \mathrm{Cl})\right]$, which is likely the dominant halogen carrier phase. Thermal metamorphism has affected abundances and halogen ratios (particularly $\mathrm{I} / \mathrm{Cl}$ ) in both the OCs and some ECs (main text Fig. 1). Petrologic types 4 to type 6 experienced varying degrees of parent body thermal metamorphism, with increasing severity from type 4 (weakly metamorphosed) to type 6 (heavily metamorphosed). In both ECs and OCs, the lowest halogen concentrations tend to occur in type 5-6, with progressively increasing concentrations in type 4 and in the least metamorphosed type 3. The lower halogen abundances in type 5 (e.g., Daniel's Kuil EL6 and St. Marks EH5) and type 6 (e.g., Novato L6) indicate severe halogen loss with progressive parent body metamorphism. The mechanism by which secondary apatite forms during thermal metamorphism (or metasomatic processes) on the OC parent bodie(s) ${ }^{86}$ may be an important factor in controlling the preserved halogen ratios.

In ECs, the extent of depletion in chlorine and bromine is not mirrored by iodine. In these samples sulphides may dominate as halogen hosts ( 12 modal \% in $\mathrm{EH}$ chondrites), including troilite (FeS) which has been suggested to host comparable amounts of iodine as silicates ${ }^{87}(\sim 1 \mathrm{ppm})$, without chlorine. The lithophile element bearing sulphide djerfisherite $\left[(\mathrm{K}, \mathrm{Na})_{6}(\mathrm{Cu}, \mathrm{Ni}, \mathrm{Fe})_{25} \mathrm{~S}_{26} \mathrm{Cl} ; \sim 1.3 \mathrm{wt}\right.$. \% chlorine $\left.{ }^{88}\right]$, is 
able to host significant chlorine. Djerfisherite in primitive ALHA 77295 (EH3) has yielded I-Xe ages of $4564.2 \pm 1.1$ and $4564.7 \pm 2.5 \mathrm{Ma}^{89}$, comparable to the age of chondrule formation in EH3 Qingzhen and Kota Kota ${ }^{90}$ and therefore has been suggested to be a nebular condensate ${ }^{91}$ as well as an important halogen-bearing phase. In some ECs, however, sulphides may decompose readily at even low temperatures ${ }^{92}$ (Extended Data Figure S5), where progressive halogen loss in the manner of $\mathrm{Cl}>\mathrm{Br}>\mid$ may be expected. Halogens in type $5-6$ chondrites have been affected by thermal processes and are therefore, unsurprisingly, not representative of their primary abundances acquired during condensation from the solar nebula.

Estimates of Bulk Silicate Earth (BSE) halogens. Bulk silicate Earth (BSE), or 'primitive mantle' (PM), is that portion of silicate crust and mantle differentiated from the metallic core, in the approximate proportions of $\sim 68$ and $32 \%$ by mass, respectively. This large reservoir is difficult to be accurately characterised for trace elements such as the halogens, but determining this global geochemical budget is essential for comparisons within the solar system and to other terrestrial planets. Early studies focused on the development of the 'pyrolite' model, developed by Ringwood ${ }^{93}$ by mixing amounts of basalt (as melt) and peridotite (as residue) with many other derivations of this model developed since ${ }^{(e . g ., 30,94)}$ based on terrestrial upper mantle samples (see Table S4). Mass balance calculations can also be used to estimate primitive mantle composition by using reservoir size and estimated reservoir concentration ${ }^{8}$ (see Table S5). Alternatively, primitive mantle estimates can be constrained using meteorite data and the assumption of chondritic refractory lithophile elements in BSE ${ }^{(e .9 .95-97)}$. Most of these different formulations result in similar chemical compositions for BSE (Table S4), for both compatible and moderately incompatible major and minor element compositions. For example, estimated BSE halogen concentrations range from 8-44 ppm chlorine, 0.045-0.4 ppm bromine and 0.007-0.04 ppm iodine (see Table S4 for references). Up to one order of magnitude variation is not unexpected given the trace nature of the halogens and the lack of data available, particularly for bromine and iodine.

Estimates for the heavy halogens in BSE are uncertain due to the low abundances of bromine and iodine, but also their difference in geochemical behavior (e.g., hydrophillic to biophilic). BSE halogen reference values are based on cosmochemical and petrological approaches and both make use of chondrite data, in 
this study those based heavily on meteorite data ${ }^{95}$ were avoided due to potential circularity in calculations.

\section{ONLINE METHOD REFERENCES:}

34. Ruzié-Hamilton, L., Clay, P.L., Burgess, R., Joachim, B., Ballentine, C.J., \& Turner, G. Determination of halogen abundances in terrestrial and extraterrestrial samples by the analysis of noble gases produced by neutron irradiation. Chem. Geol. 437, 77-87 (2016).

35. Kendrick, M. A. High precision $\mathrm{Cl}, \mathrm{Br}$ and I determinations in mineral standards using the noble gas method. Chem. Geol. 292-293, 116-126 (2012).

36. Kendrick, M. A., Arculus, R. J., Burnard, P. \& Honda, M. Quantifying brine assimilation by submarine magmas : Examples from the Galapagos Spreading Centre and Lau Basin. Geochim. Cosmochim. Acta 123, 150-165 (2013).

37. Hammerli, J., Rusk, B., Spandler, C., Emsbo, P. \& Oliver, N. H. S. In situ quantification of $\mathrm{Br}$ and $\mathrm{Cl}$ in minerals and fluid inclusions by LA-ICP-MS: A poweful tool to identify fluid sources. Chem. Geol. 337-338, 75-87 (2013).

38. Böhlke, J. \& Irwin, J. J. Brine history indicated by argon, krypton, chlorine, bromine, and iodine analyses of fluid inclusions from the Mississippi Valley type lead-fluorite-barite deposits at Hansonburg, New Mexico. Earth Planet. Sci. Lett. 110, 51-66 (1992).

39. Renne, P. R., Mundil, R., Balco, G., Min, K. \& Ludwig, K. R. Joint determination of ${ }^{40} \mathrm{~K}$ decay constants and ${ }^{40} \mathrm{Ar} *{ }^{40} \mathrm{~K}$ for the Fish Canyon sanidine standard, and improved accuracy for ${ }^{40} \mathrm{Ar} /{ }^{39} \mathrm{Ar}$ geochronology. Geochim. Cosmochim. Acta 74, 5349-5367 (2010).

40. Brazzle, R. H., Pravdivtseva, O. V, Meshik, A. P. \& Hohenberg, C. M. Verification and interpretation of the I-Xe chronometer. Geochim. Cosmochim. Acta 63, 739-760 (1999).

41. Dreibus, G. \& Wänke, H. Volatiles on Earth and Mars: A comparison. Icarus 71, 225-240 (1987).

42. Dreibus, G., Huisl, W., Spettel, B. \& Haubold, R. Halogens in nahklites: 
Studies of pre-terrestrial and terrestrial weathering processes. Lunar Planet. Sci. Conf. XXXVII, Abstr. 1180 (2006).

43. Cartwright, J. A., Gilmour, J. D. \& Burgess, R. Martian fluid and Martian weathering signatures identified in Nakhla, NWA 998 and MIL 03346 by halogen and noble gas analysis. Geochim. Cosmochim. Acta 105, 255-293 (2013).

44. Dreibus, G., Spettel, B. \& Wänke, H. Lithium and Halogens in Lunar Samples. Philos. Trans. R. Soc. A Math. Phys. Eng. Sci. 285, 49-54 (1977).

45. Reed, G. W. J. \& Jovanovic, S. The halogens in Luna 16 and Luna 20 soils. Geochemica Cosmochim. Acta 37, 1007-1009 (1973).

46. Reed, G. W. J., Jovanovic, S. \& Fuchs, L. H. Trace Elements and Accessory Minerals in Lunar Sample. Science, 167, 501-503 (1970).

47. Wänke, H., Baddenhausesn, H., Dreibus, G., Jagoutz, E., Kruse, H., Palme, H., Spettel, B. \& Teschke, F. Multielement analysis of Apollo 15, 16 and 17 samples and the bulk composition of the moon, Proc. $4^{\text {th }}$ Lunar Sci. Conf.,. 285, 1461-1481 (1973).

48. Jovanovic, S., Jemsen, K. \& Reed, G. W. J. The halogens, U, Li, Te, and $\mathrm{P}_{2} \mathrm{O}_{5}$ in five Apollo 17 soil samples. Eos Trans. Am. Geophys. Union 54, 595-596 (1973).

49. Kendrick, M. A., Woodhead, J. D. \& Kamenetsky, V. S. Tracking halogens through the subduction cycle. Geology 40, 1075-1078 (2012).

50. Kendrick, M. A., Arculus, R.J., Danyushevsky, L.V., Kamenetsky, V.S., Woodhead, J.D., \& Honda, M. Subduction-related halogens $(\mathrm{Cl}, \mathrm{Br}$ and I) and $\mathrm{H}_{2} \mathrm{O}$ in magmatic glasses from Southwest Pacific Backarc Basins. Earth Planet. Sci. Lett. 400, 165-176 (2014).

51. Kendrick, M. A., Kamenetsky, V. S., Phillips, D. \& Honda, M. Halogen systematics $(\mathrm{Cl}, \mathrm{Br}, \mathrm{I})$ in Mid-Ocean Ridge Basalts: A Macquarie Island case study. Geochim. Cosmochim. Acta 81, 82-93 (2012).

52. Schilling, J.-G., Bergeron, M. B., Evans, R. \& Smith, J. V. Halogens in the 
mantle beneath the North Atlantic. Philos. Trans. R. Soc. A Math. Phys. Eng. Sci. 297, 147-178 (1980).

53. Déruelle, B., Dreibus, G. \& Jambon, A. lodine abundances in oceanic basalts: implications for Earth dynamics. Earth Planet. Sci. Lett. 108, 217-227 (1992).

54. John, T., Scambelluri, M., Frische, M., Barnes, J. D. \& Bach, W. Dehydration of subducting serpentinite: Implications for halogen mobility in subduction zones and the deep halogen cycle. Earth Planet. Sci. Lett. 308, 65-76 (2011).

55. Kendrick, M. A. et al. Subduction zone fluxes of halogens and noble gases in seafloor and forearc serpentinites. Earth Planet. Sci. Lett. 365, 86-96 (2013).

56. Li, Y. H. A brief discussion on the mean oceanic residence time of elements. Geochim. Cosmochim. Acta 46, 2671-2675 (1982).

57. Goles, G. G. \& Greenland, P. L. Estimates of primordial halogen abundance ratios from studies of chondritic meteorites. Astron. J. 71, 162 (1966).

58. Goles, G. G., Greenland, P. L. \& Jerome, D. Y. Abundances of chlorine, bromine and iodine in meteorites. Geochim. Cosmochim. Acta 31, 1771-1787 (1967).

59. Goles, G. G. \& Anders, E. Abundances of iodine tellurium and uranium in meteorites. Geochim. Cosmochim. Acta 26, 723-737 (1962).

60. Palme, H. \& O'Neill, H. S. C. in Treatise on Geochemistry 1-39 (Elsevier Ltd., 2014). doi:10.1016/B978-0-08-095975-7.00201-1

61. Endress, M., Spettel, B. \& Bischoff, A. Chemistry, petrography and mineralogy of the Tonk Cl chondrite: preliminary results. Meteoritics 29, 462-463 (1994).

62. Greenland, P. L. \& Lovering, J. F. Minor and trace element abundances in chondritic meteorites. Geochim. Cosmochim. Acta 29, 821-858 (1965).

63. Anders, E. \& Ebihara, M. Solar-system abundances of the elements. Geochim. Cosmochim. Acta 46, 2363-2380 (1982).

64. Rubin, A. E. \& Choi, B.-G. Origin of halogens and nitrogen in enstatite chondrites. Earth, Moon Planets 105, 41-53 (2009). 
65. Greenland, P. L. Fractionation of chlorine, germanium, and zinc in chondritic meteorites. J. Geophys. Res. 68, 6507-6514 (1963).

66. Kallemeyn, G. W. \& Wasson, J. T. The compositional classification of chondrites-I. The carbonaceous chondrite groups. Geochim. Cosmochim. Acta 45, 1217-1230 (1981).

67. Lodders, K. \& Fegley, B. J. The Planetary Scientist's Companion. 371 (1998).

68. Palme, H. \& Beer, H. Abundances of the elements in the Solar System. In: Landolt-Borstein Group VI: Astronomy and Astrophysics (ed. Springer) 196221 (1993).

69. Anders, E. \& Grevesse, N. Abundances of the elements: Meteoritic and solar. Geochim. Cosmochim. Acta 53, 197-214 (1989).

70. Wasson, J. T. \& Kallemeyn, G. W. Compositions of Chondrites. Philos. Trans. R. Soc. A Math. Phys. Eng. Sci. 325, 535-544 (1988).

71. Palme, H., Suess, H. E. \& Zeh, H. D. Abundances of the elements in the Solar System. In: Landolt-BörNstein Group VI: Astronomy and Astrophysics (eds. Schaifers, K. \& Voigt, H. H.) 257-265 (Springer-Verlag Berlin Heidelberg, 1993).

72. Weisberg, M. K., McCoy, T. J. \& Krot, A. N. Systematics and Evaluation of Meteorite Classification, In: Meteorites and the Early Solar System II (eds. Lauretta, D. S. \& McSween, H. Y.) 19-52 (University of Arizona Press, 2006).

73. King, A. J., Schofield, P. F., Howard, K. T. \& Russell, S. S. Modal mineralogy of $\mathrm{Cl}$ and $\mathrm{Cl}$-like chondrites by $\mathrm{X}$-ray diffraction. Geochim. Cosmochim. Acta 165, 148-160 (2015).

74. Bland, P. A., Cressey, G. \& Menzies, O. N. Modal mineralogy of carbonaceous chondrites by X-Ray diffraction and Mössbauer spectroscopy. Meteorit. Planet. Sci. 39, 3-16 (2004).

75. Howard, K. T., Benedix, G. K., Bland, P. A. \& Schrader, D. L. Modal mineralogy of CR chondrites by PSD-XRD: Abundance of amorphous FeSilicate. $74^{\text {th }}$ Meteoritical Society Meeting abstract 5256 (2011). 
76. Menzies, O. N., Bland, P. A., Berry, F. J. \& Cressey, G. A Mössbauer spectroscopy and X-ray diffraction study of ordinary chondrites: Quantification of modal mineralogy and implications for redox conditions during metamorphism. Meteorit. Planet. Sci. 40, 1023-1042 (2005).

77. Izawa, M. R. M., King, P. L., Flemming, R. L., Peterson, R. C. \& McCausland, P. J. A. Mineralogical and spectroscopic investigation of enstatite chondrites by X-ray diffraction and infrared reflectance spectroscopy. J. Geophys. Res. 115, E07008 (2010).

78. Bischoff, A., Vogel, N. \& Roszjar, J. The Rumuruti chondrite group. Chemie der Erde 71, 101-133 (2011).

79. Vetter, W. et al. Sponge halogenated natural products found at parts-permillion levels in marine mammals. Environ. Toxicol. Chem. 21, 2014-2019 (2002).

80. Gribble, G. W. The diversity of naturally produced organohalogens. Chemosphere 52, 289-297 (2003).

81. Vogt, R., Crutzen, P. J. \& Sander, R. A mechanism for halogen release from sea-salt aerosol in the remote marine boundary layer. Nature 383, 327-330 (1996).

82. Heumann, K. G., Neubauer, J. \& Reifenhäuser, W. lodine overabundances measured in the surface layers of an Antarctic stony and iron meteorite. Geochim. Cosmochim. Acta 54, 2503-2506 (1990).

83. Dreibus, G., Wänke, H. \& Schultz, L. Mysterious iodine-overabundance in Antarctic meteorites. Lunar Planet. Sci. Inst. Int. Work. Antarct. Meteorites 3436 (1986).

84. Kendrick, M. A., Scambelluri, M., Honda, M. \& Phillips, D. High abundances of noble gas and chlorine delivered to the mantle by serpentinite subduction. Nat. Geosci. 4, 807-812 (2011).

85. Kadlag, Y. \& Becker, H. Highly siderophile and chalcogen element constraints on the origin of components of the Allende and Murchison meteorites. 
86. Jones, R. , McCubbin, R.H., Dreeland, L., Guan, Y., Burger, P.V., Sjhearer, C.K. Phosphate minerals in LL chondrites: A record of the action of fluids during metamorphism on ordinary chondrite parent bodies. Geochim. Cosmochim. Acta 132, 120-140 (2014).

87. Goswami, J. N., Sahijpal, S., Kehm, K., Hohenberg, C. M., Swindle, T.D., Grossman, J.N. In situ determination of iodine content and iodine-xenon systematics in silicates and troilite phases in chondrules from the LL3 chondrite Semarkona. Meteorit. Planet. Sci. 33, 527-534 (1998).

88. Clay, P. L., O'Driscoll, B., Upton, B. G. J. \& Busemann, H. Characteristics of djerfisherite from fluid-rich, metasomatized alkaline intrusive environments and anhydrous enstatite chondrites and achondrites. Am. Mineral. 99, 1683-1693 (2014).

89. King, A. J., Clay, P.L., Crowther, S.A., Nottingham, M., Gilmour, J.D., Wieler, R., Busemann, H. Noble gas chronology of the EH3 chondrite ALHA 77295 by closed system stepped etching. In Lunar Planet. Sci. Conf. XLIV Abstr. 2217 (2013).

90. Whitby, J. A., Gilmour, J. D., Turner, G., Prinz, M. \& Ash, R. D. lodine-Xenon dating of chondrules from the Qingzhen and Kota Kota enstatite chondrites. Geochim. Cosmochim. Acta 66, 347-359 (2002).

91. Ebel, D. S. \& Sack, R. O. Djerfisherite: nebular source of refractory potassium. Contrib. to Mineral. Petrol. 166, 923-934 (2013).

92. El Goresy, A., Yabuki, H., Ehlers, K., Wollum, D. \& Pernicka, E. Qingzhen and Yamato-691: A tentative alphabet for the EH chondrites. Proc. Natl. Inst. Polar Res. 1, 65-101 (1988).

93. Ringwood, A. A model for the upper mantle. J. Geophys. Res. 67, 858-867 (1962).

94. Jagoutz, E., Palme, H., Baddenhausen, H., Blum, K., Cendales, M., Dreibus, G., Spettel, B., Lorenz, V., \& Wänke, H. The abundance of major, minor and 
trace elements in the Earth's mantle as derived from primitive ultramafic nodules. Proc. Lunar Planet. Sci. Conf. 1, 2031-2050 (1979).

95. Allègre, C. J., Manhès, G. \& Lewin, É. Chemical composition of the Earth and the volatility control on planetary genetics. Earth Planet. Sci. Lett. 185, 46-69 (2001).

96. Palme, H. \& Nickel, K. G. Ca/Al ratio and composition of the Earth's upper mantle. Geochim. Cosmochim. Acta 49, 2123-2132 (1985).

97. Hart, S. R. \& Zindler, A. In search of a bulk-Earth composition. Chem. Geol. 57, 247-267 (1986).

98. Burgess, R., Cartigny, P., Harrison, D., Hobson, E. \& Harris, J. Volatile composition of microinclusions in diamonds from the Panda kimberlite, Canada: Implications for chemical and isotopic heterogeneity in the mantle. Geochim. Cosmochim. Acta 73, 1779-1794 (2009).

99. Sun, S.-S. Chemical composition and origin of the earth's primitive mantle. Geochim. Cosmochim. Acta 46, 179-192 (1982).

100. Anderson, D. L. Chemical composition of the mantle. Proc. Lunar Planet. Sci. Conf. 88, B41-B52 (1983).

101. Morgan, J. W. \& Anders, E. Chemical composition of Earth, Venus, and Mercury. Proc. Natl. Acad. Sci. U.S.A. 77, 6973-6977 (1980).

102. Kargel, J. S. \& Lewis, J. S. The composition and early evolution of Earth. Icarus 105, 1-25 (1993).

103. Ringwood, A. Phase transformations and their bearing on the constitution of the mantle. Geochim. Cosmochim. Acta 55, 2083-2110 (1991).

104. Jambon, A., Weber, H. \& Begemann, F. Helium and argon from an Atlantic MORB glass: concentration, distribution and isotopic composition. Earth Planet. Sci. Lett. 73, 255-267 (1985).

105. Wänke, H., Dreibus, G. \& Jagoutz, E. In: Archean Geochemistry (ed. Kroner, A.) 1-24 (Springer, 1984). 
830

831

832

833

834

835

836
106. Lyubetskaya, T. \& Korenaga, J. Chemical composition of Earth's primitive mantle and its variance: 1. Methods and results. J. Geophys. Res. Solid Earth 112, 1-21 (2007).

107. Schilling, J.-G., Unni, C. K. \& Bender, M. L. Origin of chlorine and bromine in the oceans. Nature 273, 631-636 (1978).

108. Muramatsu, Y. \& Wedepohl, K. H. The distribution of iodine in the earth's crust. Chem. Geol. 147, 201-216 (1998). 

published article and its supplementary information files. 


\section{EXTENDED DATA FIGURE LEGENDS:}

EXTENDED DATA FIGURE 1. Compilation of halogen data for $\mathrm{Cl}$ chondrites. Histograms of chlorine (A), bromine (B) and iodine (C), showing the distribution of halogens in $\mathrm{Cl}$-chondrites, as reported in Table S1. Data for Orgueil from this study are shown in each panel by the black line, with uncertainty shown in grey (for iodine, this is within the thickness of the line).

EXTENDED DATA FIGURE 2. Comparison of meteorite find environments can be used as a diagnostic tool to asses terrestrial contamination. Total halogen concentrations in hot desert, cold desert and non-desert meteorites analysed in this study.

EXTENDED DATA FIGURE 3. Comparison of chlorine in meteorite finds and falls can be used to assess terrestrial contamination. Chlorine is expected to be higher in the finds compared to falls, where contamination has occurred, due to high relative $\mathrm{Cl}$ in the terrestrial environment. However, no significant difference is observed between falls and finds, illustrating that the samples are not strongly contaminated, and some of the highest concentrations are present in the falls. This is considered to reflect variations in the amounts of halogen carrier phases present, rather than resulting from terrestrial input.

EXTENDED DATA FIGURE 4. Bromine/Cl and $\mathrm{I} / \mathrm{Cl}$ ratios in some known terrestrial contaminants as indicators of terrestrial contamination. Sample halogen ratios are shown in the context of some known terrestrial contaminants, marine aerosol, ice, and atmospheric particles from McMurdo and the South Pole. The dashed lines encompass the region of contamination. Samples are generally below these values, apart from SAH 97096 (EH3), which is affected by a contaminant with a high $\mathrm{Br}$ concentration. The composition of the contaminants is given in ref. 83 .

EXTENDED DATA FIGURE 5. Backscattered electron image of SAH 97096 shows some halogen-carrier phases are susceptible to thermal metamorphism. Sulphide breakdown reaction ${ }^{92}$ due to thermal metamorphism in enstatite chondrite SAH $97096(\mathrm{EH} 3)$. Djerfisherite $\left[(\mathrm{K}, \mathrm{Na})_{6}(\mathrm{Cu}, \mathrm{Ni}, \mathrm{Fe})_{25} \mathrm{~S}_{26} \mathrm{Cl}\right]$ breaks down into porous troilite, with loss of $\mathrm{Na}, \mathrm{K}, \mathrm{Cl}$, etc. Original djerfisherite is 
871 shown in the red boxes, while the reaction product is the large mass in the centre of 872 the image. If djerfisherite is a host to bromine and iodine as well as chlorine, halogen 873 loss may be synchronous with alteration, which could be an explanation for the 874 consistent loss of all halogens in ECs with increasing petrologic type. 
876 bromine and iodine) and ratio data as determined by NI-NGMS. Uncertainty is the

877 square root of the sum of the weight factors.

\begin{tabular}{|c|c|c|c|c|c|c|c|c|}
\hline Sample & Clan & Type & $\mathbf{N}$ & $\mathrm{Cl}$ (ppm) & $\mathrm{Br}(\mathrm{ppb})$ & I (ppb) & $\begin{array}{c}\mathrm{Br} / \mathrm{Cl} \mathrm{x} \\
10^{-3} \text { (wt.) }\end{array}$ & $\begin{array}{c}I / C I x \\
10^{-3} \text { (wt.) }\end{array}$ \\
\hline \multicolumn{9}{|c|}{ Carbonaceous Chondrites } \\
\hline Orgueil & $\mathrm{Cl}$ & 1 & 2 & $115 \pm 36$ & $189 \pm 71$ & $57 \pm 7$ & $1.6 \pm 0.1$ & $0.5 \pm 0.1$ \\
\hline Murchison & $\mathrm{CM}$ & 2 & 1 & $231 \pm 9$ & $971 \pm 56$ & $65 \pm 3$ & $4.2 \pm 0.1$ & $0.28 \pm 0.01$ \\
\hline Sutter's Mill & C? & & 2 & $218 \pm 12$ & $725 \pm 50$ & $48 \pm 4$ & $3.3 \pm 0.1$ & $0.22 \pm 0.01$ \\
\hline Murray & $\mathrm{CM}$ & 2 & 2 & $151 \pm 9$ & $123 \pm 11$ & $14 \pm 2$ & $0.8 \pm 0.1$ & $0.09 \pm 0.01$ \\
\hline EET 92159 & CR & 2 & 2 & $77 \pm 6$ & $173 \pm 22$ & $28 \pm 5$ & $2.3 \pm 0.1$ & $0.37 \pm 0.01$ \\
\hline GRA 06100 & $\mathrm{CR}$ & 2 & 2 & $60 \pm 4$ & $98 \pm 8$ & $27 \pm 2$ & $1.6 \pm 0.1$ & $0.46 \pm 0.01$ \\
\hline Allende & $\mathrm{CV}_{\text {ox }}$ & 3 & 1 & $85 \pm 3$ & $397 \pm 23$ & $35 \pm 1$ & $4.7 \pm 0.2$ & $0.41 \pm 0.02$ \\
\hline Efremovka & $\mathrm{CV}_{\text {red }}$ & 3 & 2 & $18 \pm 2$ & $50 \pm 5$ & $6 \pm 1$ & $2.8 \pm 0.1$ & $0.31 \pm 0.08$ \\
\hline \multicolumn{9}{|c|}{ Enstatite Chondrites } \\
\hline MIL 07028 & $\mathrm{EH}$ & 3 & 3 & $143 \pm 7$ & $548 \pm 79$ & $41 \pm 13$ & $3.8 \pm 0.1$ & $0.29 \pm 0.01$ \\
\hline MIL07139* & $\mathrm{EH}$ & 3 & 3 & $29 \pm 2$ & $59 \pm 6$ & $4.4 \pm 0.4$ & nd & nd \\
\hline SAH 97096* & $\mathrm{EH}$ & 3 & 1 & $13 \pm 1$ & $583 \pm 54$ & $64 \pm 6$ & nd & nd \\
\hline ALH 77295 & $\mathrm{EH}$ & 3 & 1 & $324 \pm 22$ & $982 \pm 90$ & $51 \pm 5$ & $3.0 \pm 0.1$ & $0.16 \pm 0.01$ \\
\hline Indarch & $\mathrm{EH}$ & 4 & 3 & $84 \pm 6$ & $327 \pm 34$ & $62 \pm 6$ & $3.9 \pm 0.1$ & $0.74 \pm 0.01$ \\
\hline St. Mark's & $\mathrm{EH}$ & 5 & 1 & $51 \pm 3$ & $141 \pm 15$ & $11 \pm 1$ & $2.8 \pm 0.2$ & $0.22 \pm 0.03$ \\
\hline Daniel's Kuil & $E L$ & 6 & 2 & $14 \pm 1$ & $20 \pm 2$ & $1.6 \pm 0.2$ & $1.43 \pm 0.5$ & $0.12 \pm 0.14$ \\
\hline \multicolumn{9}{|c|}{ Ordinary Chondrites } \\
\hline Clovis & $\mathrm{H}$ & 3.6 & 3 & $11 \pm 3$ & $5 \pm 2$ & $1.5 \pm 0.1$ & $0.4 \pm 0.2$ & $0.14 \pm 0.3$ \\
\hline Forest Vale & $\mathrm{H}$ & 4 & 2 & $76 \pm 15$ & $185 \pm 66$ & $22 \pm 2$ & $2.5 \pm 0.1$ & $0.28 \pm 0.01$ \\
\hline Barratta & $\mathrm{L}$ & 4 & 2 & $102 \pm 8$ & $312 \pm 31$ & $28 \pm 4$ & $3.1 \pm 0.1$ & $0.27 \pm 0.01$ \\
\hline Barwell & $\mathrm{L}$ & 5 & 1 & $278 \pm 19$ & $424 \pm 81$ & $71 \pm 7$ & $1.5 \pm 0.1$ & $0.26 \pm 0.01$ \\
\hline Novato $^{1}$ & $\mathrm{~L}$ & 6 & 1 & $5 \pm 0$ & $4 \pm 2$ & $0.3 \pm 0.1$ & $0.8 \pm 0.3$ & $0.13 \pm 0.04$ \\
\hline Novato $^{2}$ & $\mathrm{~L}$ & 6 & 1 & $14 \pm 1$ & nd & $1.7 \pm 0.3$ & nd & $0.05 \pm 0.01$ \\
\hline Bishunpur & LL & 3.15 & 2 & $400 \pm 42$ & $120 \pm 17$ & $9 \pm 2$ & $0.3 \pm 0.1$ & $0.13 \pm 0.04$ \\
\hline Chelyabinsk & $\mathrm{LL}$ & 5 & 31 & $16 \pm 1$ & $25 \pm 9$ & nd & $1.5 \pm 0.1$ & nd \\
\hline \multicolumn{9}{|c|}{ Rumuruti Chondrites } \\
\hline NWA 755 & $\mathrm{R}$ & 3.7 & 2 & $53 \pm 3$ & $225 \pm 15$ & $29 \pm 3$ & $4.3 \pm 0.1$ & $0.55 \pm 0.01$ \\
\hline NWA 753 & $\mathrm{R}$ & 3.9 & 2 & $230 \pm 12$ & $535 \pm 26$ & $108 \pm 11$ & $2.3 \pm 0.1$ & $0.47 \pm 0.01$ \\
\hline \multicolumn{9}{|l|}{ Other } \\
\hline Kakangari & $\mathrm{K}$ & 3 & 2 & $45 \pm 4$ & $13 \pm 1$ & $3.0 \pm 0.4$ & $0.29 \pm 0.01$ & $0.07 \pm 0.06$ \\
\hline $\begin{array}{l}\text { Reported valu } \\
{ }^{*} \text { minimum cor } \\
\text { 1: Novato 'da } \\
2: \text { Novato 'ligh } \\
\mathrm{N} \text { : number of } \\
\mathrm{nd}=\text { not deter }\end{array}$ & $\begin{array}{l}\text { repres } \\
\text { entratio } \\
\text { litholog } \\
\text { litholog } \\
\text { quots a } \\
\text { nable }\end{array}$ & $\begin{array}{l}\text { nt the } t \\
\text { values, } \\
\text { alysed }\end{array}$ & tios & $\begin{array}{l}\text { NI-NGMS } \\
\text { t reported; }\end{array}$ & ee online $\mathrm{M}$ & $\begin{array}{l}\text { sion or mu } \\
\text { thods }\end{array}$ & ti-step-heatin & experiments \\
\hline
\end{tabular}

